\title{
PEDAGOGIA DO CUIDAR: UMA NOVA PERSPECTIVA PARA A ENFERMAGEM
}

\section{ARTIGO DE REVISÃO}

BARROS, Alexsandra Gomes ${ }^{1}$

SÁ-SILVA, Jackson Ronie ${ }^{2}$

BARROS, Alexsandra Gomes. SÁ-SILVA, Jackson Ronie. Pedagogia do cuidar: Uma nova perspectiva para a enfermagem. Revista Científica Multidisciplinar Núcleo do Conhecimento. Ano 05, Ed. 10, Vol. 02, pp. 59-72. Outubro de 2020. ISSN: 2448-0959, Link de acesso: https://www.nucleodoconhecimento.com.br/pedagogia/pedagogia-do-cuidar

1 Graduada em Pedagogia pela Universidade Estadual do Maranhão (UEMA); Especialista em Docência do Ensino Superior (UCAM); Especialista em Gestão, Supervisão e Orientação Educacional (Faculdade Santa Fé). Membro do Grupo de Pesquisa Ensino de Ciências, Saúde e Sexualidade da Universidade Estadual do Maranhão (GP-ENCEX / UEMA).

2 Professor Adjunto do Departamento de Biologia da Universidade Estadual do Maranhão (DBIO - UEMA / São Luís, Maranhão, Brasil); Pós-Doutor em Educação pela Faculdade de Educação da Universidade Federal do Rio Grande do Sul (FACED - UFRGS); Doutor em Educação pelo Programa de Pós-Graduação em Educação da Universidade do Vale do Rio dos Sinos (PPGE - UNISINOS); Mestre em Saúde e Ambiente pela Universidade Federal do Maranhão (UFMA); Professor do Programa de Pós-Graduação em Educação da Universidade Estadual do Maranhão - Mestrado Profissional (PPGE - UEMA). Líder do Grupo de Pesquisa Ensino de Ciências, Saúde e Sexualidade (GP-ENCEX / UEMA). 


\section{RESUMO}

A Enfermagem tem o cuidar como objeto de seu estudo, aprofundamento e ação. A Pedagogia, a educação. Enfermagem e Pedagogia complementam-se em sentido teórico e prático ao tratarem sobre seus objetos. Dois questionamentos são centrais na discussão que se apresenta nessa problematização em formato de pesquisa bibliográfica, assentada em abordagem qualitativa, cuja análise se baseou nos pressupostos da investigação documental: há uma pedagogia específica da enfermagem? Poderia se falar em pedagogia na enfermagem ao tratar-se sobre o cuidar e o educar? $\mathrm{O}$ artigo tem a intenção de refletir sobre a Pedagogia do Cuidar, sinalizando novos horizontes para a ciência Enfermagem enquanto campo do conhecimento que realiza, em suas práticas, educação em saúde, em meio a processos formais de educação via Pedagogia. Compreendemos que existe uma Pedagogia na Enfermagem, ou seja, pressupostos teóricos da ciência Pedagogia embasam o fazer educativo da Enfermagem, dando corpo à ação educativa, ainda que em âmbito da saúde.

Palavras-chave: Pedagogia e enfermagem, pedagogia na enfermagem, pedagogia da enfermagem, cuidado, formação.

\section{INTRODUÇÃO}

A Enfermagem tem o cuidar como objeto de seu estudo, aprofundamento e ação, visando a saúde e bem-estar das pessoas e da comunidade; busca o ato de educar como uma de suas principais práticas, entendendo que o sujeito deve ter o conhecimento como instrumento para a construção de uma saúde integral. Assim é que $o$ ato de educar é, também, cuidar.

Algo semelhante ocorre com a ciência Pedagogia, que tem no ato de educar o cuidar, pois, sem conhecimento, as pessoas não alcançariam a condição de cidadãos, favorecendo possibilidades de intervenção e transformação das realidades. 
Observamos que as ciências Enfermagem (cuidar) e Pedagogia (educação) partilham de iguais objetos de saber, em meio aos seus desdobramentos teóricos e práticos, pois o cuidar e o educar revelam-se como processos comuns em suas rotinas e propósitos, devendo ser a pedagogia do cuidar um ato intencional, traduzido por uma metodologia problematizadora e interdisciplinar, onde o profissional da saúde precisará fundamentar-se em uma formação, inicial e continuada, que valoriza os processos educativos, além dos conhecimentos específicos da área de Enfermagem.

O sentido de cuidar é uma construção da Enfermagem, como o educar é da Pedagogia. O cuidar nasceu espontâneo/natural, intuitivo/como arte, tradicional, ganhando, no decurso do tempo, sistematizações/saberes científicos, o que garantiu autonomia e identidade aos profissionais da Enfermagem. Diferente não é o percurso da Pedagogia, se comparado ao da Enfermagem; foram séculos de construções, reconstruções e desconstruções para chegarmos ao status atual da ciência e de suas implicações.

Assim surgiu o tema PEDAGOGIA DO CUIDAR: UMA NOVA PERSPECTIVA PARA A ENFERMAGEM, tentando identificar uma Pedagogia própria da Enfermagem ou uma Pedagogia histórica, científica, técnica e humana que também alcança, por interdisciplinaridade, a ciência Enfermagem.

Posto isso, problematizamos, há uma pedagogia específica da enfermagem? Poderia se falar em pedagogia na enfermagem ao tratar-se sobre o cuidar e o educar?

O tema, de relevância acadêmica e profissional, analisa a construção do discurso e da prática do cuidar educando, hipotetizando que não apenas princípios científicos e técnicos são capazes de embasar a ação humanizada e política do profissional enfermeiro, buscando nos horizontes da ciência Pedagogia elementos necessários, teóricos e práticos, para o materializar de uma ação do cuidar educando mais assertiva. 
O artigo tem a intenção de nos fazer refletir sobre a Pedagogia do Cuidar, sinalizando novos horizontes para a ciência Enfermagem, interdisciplinarizando conhecimentos e ações com a Pedagogia, em meio a processos formais de educação.

Realizamos uma pesquisa bibliográfica, assentada em abordagem qualitativa, cuja análise se baseou nos pressupostos da investigação documental vislumbrada por Almeida, Guindani e Sá-Silva (2009). O processo de análise do conteúdo dos doze artigos catalogados, especificamente quanto ao tema, foi desenvolvido a partir do estudo categorial de Bardin (2016).

\section{DESENVOLVIMENTO}

\subsection{O SIGNIFICADO DE CUIDAR E CUIDADO PARA A ENFERMAGEM}

O sentido de cuidar e cuidado para a Enfermagem foi se configurando na própria evolução da ciência e da profissão. Para Souza (1988), por muito tempo, o cuidado em Enfermagem deu-se de maneira espontânea, intuitiva e tradicional, como arte. Apenas no século XX é sistematizado a partir de técnicas.

Nos anos de 1950, surgem questionamentos sobre o cuidar de maneira tecnicamente orientada, quando são incorporados à prática de enfermagem saberes científicos. $\mathrm{Na}$ década de 1960, busca-se elaborar modelos conceituais e teorias da enfermagem, visando, também, conferir identidade e autonomia à profissão.

O cuidado ao ser humano se insere na história como uma atividade ligada à cura das doenças, ao alívio do sofrimento físico e mental. Assim, a concepção acerca da doença e da saúde sempre determinou princípios ou maneiras de praticar o cuidado orientando-se pelos valores predominantes na sociedade. (GONÇALVES e SENA,1999, p.02)

Oliveira; Paula e Freitas (2007) citam as Teorias de Enfermagem que, majoritariamente, foram elaboradas nos anos de 1960 e 1970: Hildegard E. Peplau e a teoria do relacionamento interpessoal, Dorothea Orem e a teoria do déficit de autocuidado, Martha Elizabeth Rogers e a teoria humanística e humanitária, Madeleine M. Leininger e a teoria da enfermagem transcultural, Jean Watson e a teoria 
do cuidado transpessoal e Wanda Horta e a teoria das necessidades humanas básicas, valorizando o cuidado ao ser humano.

De acordo com Horta (1974), a Teoria das Necessidades Básicas, apoiada em Maslow, pressupõe: a enfermagem é um serviço prestado às pessoas. A enfermagem implementa estados de equilíbrio, previne estados de desequilíbrio e reveste desequilíbrios em equilíbrio pela assistência, no atendimento de suas necessidades básicas. Procura sempre reconduzir o sujeito à situação de equilíbrio dinâmico no tempo e espaço, atribuindo sentido ao cuidar.

Em 1985, a estudiosa e pesquisadora Meleis, conforme Alcântara et al. (2011), classificou as teorias de enfermagem.

Passaremos, no presente parágrafo, a citar apenas as classificações que complementam a sistematização já apresentada: teoria ambientalista (1958), teoria das necessidades básicas (1955), teoria prescritiva do cuidado (1958), teoria humanista (1960), teoria do processo de enfermagem (1961), teoria homeostática (1961), teoria do alcance de objetivos (1964), teoria da pessoa, do cuidado e da cura (1966), teoria da conservação de energia e da enfermagem holística (1967), teoria sinergística (1969), teoria da adaptação (1970), teoria dos sistemas de Neumam (1974), teoria do vir-a-ser-humano (1981), teoria rítmica de enfermagem (1983), teoria da modelagem do papel (1983), teoria da construção do auto conceito (1985), teoria da saúde como consciência expandida (1986), teoria geral da enfermagem (1993) e teoria do controle de estresse (1995).

Buscando aproximar as teorias mencionadas acima ao objeto de nossa análise, entendemos que tais estruturas, muito embora não tratem diretamente sobre educação, uma vez que não ser o fundamento principal de suas abordagens, elas desenvolvem o processo educativo ao proporem e executarem o cuidar das pessoas.

Hoje, o cuidado assume novas dimensões como um produto que se diversificou em inúmeras atividades, tornando-se parte integrante da realidade histórica, política, econômica, cultural e social.[...] entendemos o cuidado como um trabalho humano [...]. Trabalho social e econômico que se elabora através do ato pensado, realizado e recriado [...]. A 
concretização do cuidado sustenta-se na concepção de um trabalho dirigido a indivíduos e à coletividade. Organiza-se com base nos valores e crenças que orientam eticamente as relações entre os sujeitos envolvidos no ato de cuidar. Dessa forma, o cuidado expressa-se em atividades que, em sua maioria, se consomem no ato de sua realização por cuidadores conscientes de seu projeto e execução e, nem sempre conscientes dos seus resultados e consequências. (GONÇALVES e SENA, 1999, p. 2 e 3)

O cuidado em Enfermagem e a própria identidade profissional perpassam por princípios gerais, teorias e padrões universais, não restringindo-se mais a ações intuitivas.

$\mathrm{Na}$ tentativa de ainda conceituar o cuidado e refletir sobre suas definições, citamos:

Cuidado de enfermagem: É a ação planejada, deliberativa ou automática [...], resultante de sua percepção, observação e análise do comportamento, situação ou condição do ser humano. O cuidado de enfermagem pode implicar em várias atividades, por exemplo, a higiene oral - verificar o material que o paciente possui; avaliar sua capacidade de autocuidado; observar condições da cavidade bucal; explicar o cuidado ao paciente; ensinar, se necessário, a técnica adequada de escovação; encaminhar ao odontólogo; lavar o material utilizado; anotar, etc... (HORTA, 1974, p. 13)

Para Quadros et al. (2009, p. 01) "O cuidado [...] consiste na atenção para cuidar do outro, visando suprir as necessidades do cliente a ser cuidado".

O cuidado tem relação com a educação, pois as pessoas não compreenderiam e agiriam coerentemente conforme a sua necessidade (profissional e pessoal) sem ter vivenciado o processo educativo, que remete à aprendizagem.

Para tal, uma ciência específica, a pedagógica, precisa fundamentar 0 ato metodológico e político de quem educa, assegurando ao sujeito aprendente saberes que o qualifiquem a sua condição cidadã e transformadora, pois sem ter o conhecimento como instrumento de poder, o homem entenderia apenas a específica relação saúde-doença-cura, sem analisar todas as dimensões da sua vida pessoal e em comunidade, objetivando o equilíbrio fundamental para sua existência significativa no mundo, relacionando-se com o meio. 


\subsection{PENSANDO UM POUCO SOBRE A PEDAGOGIA DO CUIDAR}

Ao observarmos a docência na Enfermagem, nos deparamos, em maioria, com bacharéis que, além da docência, assumem postos de trabalho em suas áreas de formação específicas, atribuindo, contraditoriamente, maior valor ao campo profissional da saúde, em detrimento do campo da educação, encontrando sentido para tal prática na precarização da profissionalização docente no Brasil.

Para Rodrigues e Sobrinho (2007), muitos docentes (graduados em Enfermagem) construíram suas identidades profissionais no setor da educação, considerando suas experiências ao longo da vida escolar ${ }^{9}$, sem qualquer formação específica no campo pedagógico, embora isto seja fundamental, bastando observar os imperativos da sociedade do século XXI e as demandas feitas ao processo de ensino e aprendizagem na educação superior.

[...] existe uma fragilidade nas etapas de formação do enfermeiro que não o capacitam para atuar na docência. [...] eles aprenderam a ministrar aulas baseados em seus professores que tinham como símbolos, na época em que eram discentes. Com isso, surge a necessidade de aperfeiçoamento [...] (RIBEIRO et al., 2018, p. 299)

Acredita-se que o profissional enfermeiro atribua importância ao processo pedagógico, entre outras questões, quando tem a clareza da sua validade para o ensino, pois sua materialidade também se expressa no cuidado que presta ao sujeito aluno ou paciente, o que pressupõe a necessidade de formação inicial e continuada do docente enfermeiro, considerando a Pedagogia como fundamento.

Assertivamente, Rodrigues e Sobrinho (2007, p. 457) comentam que "Faz-se necessária a capacitação contínua de preparo técnico, teórico e pedagógico inserida no contexto econômico, político, social e cultural para que haja transformações no ensino de Enfermagem", do contrário teremos como produto uma formação insuficiente da/na enfermagem.

A Educação em Saúde faz parte do cuidado de enfermagem, pois na essência somos educadores, embora Educação em Saúde por muito tempo tenha sido associada somente a procedimentos didáticos de 
transmissão de conhecimento em saúde, visando principalmente a medidas preventivas. Ainda hoje, muitos profissionais de saúde se mantêm orientados por essa visão reducionista e positivista da Educação em Saúde, entretanto a mudança de paradigma possibilita a compreensão da ciência em um nível bem mais crítico e criativo, no qual Educação e Saúde passam a ser entendidas como áreas de conhecimento humano que, integradas, revigoram o exercício da cidadania. (CHAGAS et al., 2009, p. 37 e 38)

As DCN (Diretrizes Curriculares Nacionais) sistematizam uma orientação do currículo, da metodologia e da avaliação a ser desenvolvida na prática educativa, de acordo com Rodrigues e Sobrinho (2007), valorizando os cenários da ciência, da educação e da própria sociedade. Posto isso, há a necessária de aproximação do conteúdo teórico ao conteúdo prático, alimentando a experiência concreta do graduando.

Para Menezes e Novaes (2018), a formação inicial e continuada, tendo como foco a prática, a realidade, os problemas de saúde e sociais, o serviço etc., permitirá uma visão mais contextual e problematizadora do docente/enfermeiro.

Neste cenário, compreendemos que os pressupostos educativos se concretizam por um ato pedagógico intencional, em que o educador/enfermeiro não está apenas impregnado por suposições, visto que a ação educativa não é neutra, devendo ser política e transformadora. É nesse sentido que teremos a cidadania como resultado do processo educativo.

Aqui, indiscutivelmente, evocamos a ciência Pedagogia no processo de formação, tentando responder aos questionamentos já apresentados na introdução do presente artigo.

Iniciamos uma reflexão sobre a presença de uma pedagogia específica da enfermagem ou na enfermagem ao tratar-se sobre o cuidar educando.

Compreendemos que a Pedagogia é uma ciência que tem como objeto de investigação o fenômeno educação, o processo de ensino e aprendizagem. Pela própria lógica da formação em Enfermagem, o fenômeno educação não é a sua principal pauta, mas um objeto que surge diante da necessidade do cuidar. 
Assim pensamos a Pedagogia do Cuidar, percebendo que na prática educativa da Enfermagem há pressupostos pedagógicos, qualificando o entendimento sobre a existência da ciência Pedagogia na prática educativa e cuidadora da Enfermagem.

Não compreendemos, portanto, que há uma Pedagogia específica da Enfermagem, pois a Pedagogia, como ciência, não poderá reduzir-se a mero mecanismo de ensino (técnica) da ciência Enfermagem.

Nesse sentido, é oportuno tratarmos sobre os limites e possibilidades da Pedagogia na Enfermagem, ou seja, da Pedagogia do Cuidar.

É preciso ter como horizonte a prática de uma pedagogia do cuidado de enfermagem capaz de sustentar o ato de educar como um cuidado e o assistir/cuidar como um ato de educar. Deve-se transpor para a práxis da pedagogia da enfermagem uma metodologia capaz de transformá-la em um ato social intencional, dirigido à causa da defesa da vida. (GONÇALVES e SENA, 1999, p. 04)

$\mathrm{Na}$ Pedagogia do Cuidar somos implicados por dois objetos interdisciplinares - cuidar e educar -, que se manifestam como problema para a ciência Enfermagem.

A Enfermagem, ao longo da sua história, vem priorizando um rito educacional fragmentário/cartesiano quando da promoção de uma educação para o cuidar, tendo como base somente os conhecimentos da área de saúde, sem importar-se com a dinâmica pedagógica para a materialização do conhecimento na vida do usuário dos serviços de saúde, o que pressupõe um limite, além de conceitual, procedimental e atitudinal.

O ser humano é sujeito e objeto de trabalho na enfermagem, ao mesmo tempo em que é único e diverso. Logo, a enfermagem deve considerálo em sua totalidade, respeitar o modo de viver de cada pessoa e as suas particularidades, procurar compreender as diversas influências e determinações que poderão induzir o seu modo de ser no mundo. (PINTO et al., 2017, p. 105)

Como possibilidade, tem-se o repensar do trato dos objetos - cuidar e educar - pela ciência Enfermagem, refletindo e otimizando ações interdisciplinares com a Pedagogia, favorecendo, por tal via, um comportamento profissional assertivo do 
enfermeiro (em espaço de formação ou de saúde) nos horizontes da Pedagogia do Cuidar.

É fundamental entender, na perspectiva em análise, de acordo com Chagas et al. (2009, p. 38), o ato de educar como um ato de emancipação pessoal, do homem e da própria comunidade, compreendendo que a educação e o cuidado são interdependentes. "A partir do momento em que o enfermeiro está cuidando, ele está educando e aprendendo."

Observando as práticas pedagógicas e da enfermagem analisa-se que tanto os professores como os enfermeiros cuidam e educam simultaneamente em suas funções profissionais. Portanto o cuidado e a educação são práticas naturalmente interdisciplinares, complementares e indissociáveis. (QUADROS et al., 2009, p. 01)

Com o objetivo de melhor entender pressupostos sobre a interdisciplinaridade, seguimos com algumas considerações:

- parte de situações-problema, identificando o objeto de estudo;

- articula ciências conforme a necessidade de investigação, visando a produção e socialização de resultados, pois os saberes estão a serviço das demandas expressas pelo homem, sendo estes missão do espaço formador universitário;

- é um misto de problematização, contextualização e flexibilização;

- problematização quando pensa o objeto nele mesmo. Contextualização quando coloca o objeto em uma rede de relações. Flexibilização quando traz para a discussão questões de relevância social, enriquecendo o objeto de investigação;

- a interdisciplinaridade, como na produção de qualquer conhecimento, como o transdisciplinar, comunica-se por afirmação, negação e complementação, considerando que o mundo não é apenas desvendado por concordâncias; as opiniões contrárias são fundamentais para o próprio enriquecimento das ciências em geral. 
Sabemos que as enfermeiras e os enfermeiros, uma vez bacharéis, são desqualificados, em suas formações iniciais e continuadas, para pensarem a Pedagogia do Cuidar.

O processo de formação inicial do docente enfermeiro - graduação e pós-graduação - expressa-se com consideráveis restrições pedagógicas, o que termina por empobrecer o percurso educacional de formação discente (aluno e professor), evidenciando hiatos em sua prática educativa e do cuidar, o que representa grande limite ao desenvolvimento da Pedagogia do Cuidar.

O despreparo para atuar na docência pode configurar-se como um entrave, não somente no aspecto didático-pedagógico, mas no processo como um todo. Muitas vezes, o enfermeiro docente não se percebe suficientemente instrumentalizado para agir em seu contexto de atuação, o qual não favorece o desenvolvimento de uma ação docente de qualidade que prime pelo desenvolvimento do estudante pela qualidade da assistência dos serviços prestados [...]. (DUARTE; LUNARDI e BARLEM, 2016, p. 07)

Se por um lado há restrições pedagógicas, tem-se, por outro, a potencialização dos processos específicos de conhecimento científico e técnico da área de Enfermagem na formação, potencializando a graduação de profissionais que supervalorizam as questões próprias da Enfermagem em detrimento das questões educativas, o que nos remete ao discurso de precarização da profissionalização docente no Brasil, anteriormente apresentando no presente artigo como limitação para o exercício significativo do professor de Enfermagem, e nos permite uma análise para além do discurso.

Rodrigues e Sobrinho (2007), fundamentados em Schön (2000), entendem que na formação docente, há que se considerar uma tríade: reflexão na ação, sobre a ação e sobre a reflexão na ação, qualificando o educador ao melhor direcionamento do seu fazer pedagógico, pois as dimensões científica, técnica, tecnológica, humana, política precisarão ser valorizadas para o cumprimento da responsabilidade social do ensino - do educar cuidando. 
Diante do compromisso com a educação e a formação de recursos humanos, evidencia-se a complexidade das ações do enfermeiro docente que, além de cuidar, assume a responsabilidade de ensinar o cuidado. Esse é um grande desafio, pois é preciso que se tenha a consciência de que competências técnicas não são suficientes para o desenvolvimento do cuidado, fazendo-se necessária a construção do conhecimento com vistas à formação ética, à capacidade de empoderamento de sua prática, à empatia e à solidariedade no âmbito do fazer. (DUARTE; LUNARDI e BARLEM, 2016, p. 07)

Ao pensarmos nas restrições quanto à formação inicial dos enfermeiros bacharéis, tem-se a formação continuada como importante recurso de complementação teórica e prática, na tentativa de reparar os hiatos pedagógicos deixados na formação inicial, representando um caminho concreto e virtuoso para o trabalho com a Pedagogia do Cuidar.

Nesse entendimento, concordamos com Oliveira; Paula e Freitas (2007), ao mencionarem que a sistematização apresentada por Wanda de Aguiar Horta, que evoca o histórico, o diagnóstico, o plano assistencial, o plano de cuidados ou prescrição, a evolução e o prognóstico de enfermagem, faz parte de um grande planejamento e ação do cuidar (da instituição e do profissional da saúde e da educação em saúde), que valoriza o educar em seu processo e a metodologia problematizadora como alternativa para a sua plena significação.

A metodologia problematizadora é um dos pilares interdisciplinares, que aqui já foi referida, nos permitindo melhor qualificar e quantificar o objeto de investigação.

Ratificamos que o cuidar e o educar não podem ser entendidos, na trama da Pedagogia do Cuidar, dissociados.

Pensar a Pedagogia não nos parece uma única obrigatoriedade dos espaços profissionais de saúde, mas, sobretudo, dos espaços de educação superior - em Enfermagem, visto que a educação do século XXI expressa demandas generalistas para o profissional enfermeiro, demandas que a educação cartesiana não tem e não terá condições de responder. 
Sem uma Pedagogia compreendida e aplicada, em sua complexidade, na saúde, não teremos respostas e experiências concretas quanto à efetividade da Pedagogia do Cuidar. Nos parece ser evidente que a Enfermagem precisa melhor dialogar com a Pedagogia, produzindo, por teoria e ação, a Pedagogia do Cuidar.

\section{CONSIDERAÇÕES FINAIS}

Revisitamos com o presente artigo os objetos de investigação e trabalho da Enfermagem (cuidar) e da Pedagogia (educar). Entendemos que, pela ação cuidadora e educativa da Enfermagem, os objetos cuidar e educar estão interdisciplinarizados com a Pedagogia, observando a metodologia da problematização e a intencionalidade docente como pressupostos da Pedagogia do Cuidar.

A Pedagogia do Cuidar é a materialização consciente e emancipadora do ato de cuidar educando e de educar cuidando, ultrapassando a visão reducionista da saúdedoença-cura.

Compreendemos que existe uma Pedagogia na Enfermagem, ou seja, pressupostos teóricos da ciência Pedagogia embasam o fazer educativo da Enfermagem, dando corpo à ação educativa, ainda que em âmbito da saúde.

Nesse sentido, identificamos que não temos uma Pedagogia da Enfermagem, assim como temos as Pedagogias tradicional, tecnicista, escolanovista, libertadora, críticosocial dos conteúdos, construtivista etc., uma vez que a Enfermagem não tem como objeto principal discutir a educação, como as demais pedagogias aqui expressas.

O bacharel em Enfermagem não tem elementos pedagógicos para o trabalho educativo do cuidar, tendo muito mais atenção e dedicação aos elementos específicos da saúde em detrimento das dimensões pedagógicas que permitem um processo educativo mais significativo.

Assim, avaliamos a formação continuada como possibilidade de complementação da formação do bacharel em enfermagem, enriquecendo o elemento pedagógico inicialmente preterido. 
Concluímos que a formação continuada deve ser uma obrigatoriedade dos espaços formativos e profissionais da saúde, em especial, dado o campo de análise do artigo, da Enfermagem.

O presente artigo é ainda um começo para pensar a Pedagogia do Cuidar, intencionando o prosseguimento do estudo, haja vista sua importância acadêmica.

\section{REFERÊNCIAS}

ALCÂNTARA, Marcos Roberto de; SILVA, Damiana Guedes de; FREIBERGER, Mônica Fernandes; COELHO, Milena Pietrobon Paiva Machado. Teorias de Enfermagem: a importância para a implementação da sistematização da assistência de enfermagem, Revista Científica FAEMA, 2011, 2(2): 115-132, maiooutubro, 2011. Disponível em http://www.faema.edu.br/revistas/index.php/RevistaFAEMA/article/view/99. Acesso em 30/06/2020 junho.

BARDIN, Laurence. Análise de conteúdo. São Paulo: Edições 70, 2016.

CHAGAS, Natália Rocha; RAMOS, Islane Costa; SILVA, Lúcia de Fátima da; MONTEIRO, Ana Ruth Macêdo; FIALHO, Ana Virgínia de Melo. Cuidado Crítico e Criativo: contribuições da educação conscientizadora de Paulo Freire para a enfermagem, Ciencia y Enfermería, vol. XV, 2009, núm. 2, 35-40, agosto 2009. Disponível em: http://www.redalyc.org/articulo.oa?id=370441799005. Acesso em 17/06/2020.

DUARTE, Carla Godinho; LUNARDI, Valéria Lerch; BARLEM, Edison Luiz Devos, Satisfação e Sofrimento no Trabalho do Enfermeiro Docente: uma revisão integrativa, REME - Rev. Min. Enferm. 2016, 20:e939, 2016. Disponível em: http://www.reme.org.br/artigo/detalhes/1073. Acesso em 18/07/2020.

GONÇALVES, Alda Martins; SENA, Roseni Rosangêla de. A pedagogia do cuidado de enfermagem, REME rev. min. Enferm, 1999, 3(1/2): 41-5, jan-dez 1999.Disponível em https://pesquisa.bvsalud.org/portal/resource/pt/bde-26574. Acesso em 01/07/2020. 
HORTA, Wanda de Aguiar. Enfermagem: teoria, conceitos, princípios e processo. Rev. esc. enferm. USP, 1974, 8(1):7-17, 1974.Disponível em: https://www.scielo.br/scielo.php?pid=S0080-

62341974000100007\&script=sci_abstract\&tIng=pt. Acesso em 22/06/2020.

MENEZES, Kátia Rodrigues; NOVAES, Maria Rita Carvalho Gabi. Formação Pedagógica de Professores de Graduação em Enfermagem: revisão integrativa da literatura, CCS Comunicação em Ciências da Saúde, 2018, 29(4); 243 - 54. Disponível

em: http://www.escs.edu.br/revistaccs/index.php/comunicacaoemcienciasdasaude/a rticle/view/336. Acesso em 05/08/2020.

OLIVEIRA, Marcela Lino de; PAULA, Taís Romano de; FREITAS, João Batista de. Evolução Histórica da Assistência de Enfermagem, ConScientiae Saúde, vol 06, núm. $\quad 01.2007,127-36 . \quad$ Disponível em: https://periodicos.uninove.br/index.php?journal=saude \&page=article \&op=view\&path \%5B\%5D=919\&path\%5B\%5D=788. Acesso em 30/07/2020.

PINTO, Anaísa Cristina; GARANHANI, Mara Lúcia; FRANÇA, Thiago Eduardo de; PIEROTTI, Isadora. Conceito de Ser Humano nas Teorias de Enfermagem: aproximação com o ensino da condição humana, Pro-Posições, vol 28, 2017, 88 110 , 2017.

Disponível em: https://www.scielo.br/scielo.php?script=sci_abstract\&pid=S010373072017000400088\&lng=pt\&nrm=iso. Acesso em 07/06/2020.

QUADROS, Vanessa Franco de; GARCIA, Maria Isabella Haslett; MEZA, Miriam Elisa Riveiro; VIEIRA, Patrícia Silva; SOUZA, Itatiana Oliveira de; DIAS, Francisleide Rodrigues Andrade; ANADON, Simone. Enfermagem e Pedagogia: a junção entre - cuidado e educação -um relato de experiência, 2009.Disponível em https://propesp.furg.br/anaismpu/cd2009/ensino/317-274-1-SM.pdf. Acesso em 05/06/2020. 
RIBEIRO, José Francisco; COSTA, Jéssica Moura Luz; SILVA, Maria Aparecida Coutinho da; LUZ, Vera Lúcia Evangelista de Sousa; VELOSO, Marylane Vieira, Ribeiro; COELHO, Dalila Maria Matías. Prática Pedagógica do Enfermeiro na Docência do Ensino Superior. Revista de Enfermagem, 2018, 291 - 302. Disponível em https://periodicos.ufpe.br/revistas/revistaenfermagem/article/view/25129/27792. Acesso em 12/07/2020.

RODRIGUES, Malvina Thaís Pacheco; SOBRINHO, José Augusto de Carvalho Mendes. Enfermeiro professor: um diálogo com a formação pedagógica, Rev. bras. enferm., 2007, 456-59, maio-junho de 2007. Disponível em http://dx.doi.org/10.1590/S0034-71672007000400019. Acesso em 03/08/2020.

SÁ-SILVA, Jackson Roni; ALMEIDA, Cristóvão Domingos de; GUINDANI, Joel Felipe. Pesquisa documental: pistas teóricas e metodológicas, Revista Brasileira de História \& Ciências Sociais, 2009, núm. 01, 01 -15, julho 2009. Disponível em: https://periodicos.furg.br/rbhcs/article/view/10351/pdf. Acesso em 12/08/2020.

SCHÖN, Donald A. Educando o profissional reflexivo: um novo design para o ensino e a aprendizagem. Porto Alegre (RS): Artmed, 2000.

SOUZA, Mariana Fernandes de. Teorias de Enfermagem: importância para a profissão, Acta Paulista de Enfermagem, 1988,1(3): 63-5, setembro 1988. Disponível em: https://acta-ape.org/wp-content/uploads/articles_xml/1982-0194-ape-S010321001988000100015/1982-0194-ape-S0103-21001988000100015.x45416.pdf. Acesso em 10/07/2020.

Enviado: Agosto, 2020.

Aprovado: Outubro, 2020. 